\title{
Development and Validation of a Precise RP- HPLC Method to Determine Gentiopicroside Content in Cultures of Gentiana kurroo Royle
}

\author{
Mariadoss Alphonse ${ }^{1}$, Rajasekaran Chandrasekaran ${ }^{1, \#}$, Michael Pillay², Devanand P Fulzele ${ }^{3}$, \\ Siva Ramamoorthy ${ }^{1}$, Kalaivani Thiyagarajan ${ }^{1, \#, *}$
}

${ }^{1}$ Department of Biotechnology, School of Biosciences and Technology, Vellore Institute of Technology, Vellore, Tamil Nadu, INDIA. ${ }^{2}$ Department of Biotechnology, Vaal University of Technology, Private Bag X021, Vanderbijlpark, SOUTH AFRICA.

${ }^{3}$ Plant Biotechnology and Secondary Metabolites Section, Nuclear Agriculture and Biotechnology Division, Bhabha Atomic Research Centre, Mumbai, Maharashtra, INDIA.

\begin{abstract}
Background: Gentipicroside (GPD) is a major bioactive seco-iridoid glycoside in the methanolic extracts of roots and rhizomes of Gentiana kurroo Royle. GPD has antiinflammatory, antidiabetic, analgesic, antinociceptive, antibacterial and free radical scavenging activities. Although this compound was analyzed by various methods in different Gentiana species previously, no valid method was documented describing the accuracy and precision for the detection and quantification of GPD from in vitro samples of G. kurroo. Materials and Methods: A simple, accurate and highly sensitive reversed-phase high-performance liquid chromatographic (RP-HPLC) method was developed and validated according to the International Conference on Harmonization (ICH) guidelines. Results: Methanol and $0.1 \%$ acetic acid in millipore water [30:70, (v/v)] was used as a mobile phase and eluted at an isocratic flow rate of $1.0 \mathrm{ml} / \mathrm{min}$ under room temperature. The calibration curve was linear in the concentration range of 10-100 $\mu \mathrm{g} / \mathrm{ml}$ with a correlation coefficient of 0.9967 . The relative standard deviation (RSD) of repeatability and inter-day precision was less than $2 \%$. The limit of detection (LOD) and limit of quantification (LOQ) of GPD was $0.083 \mu \mathrm{g} / \mathrm{ml}$ and $0.25 \mu \mathrm{g} / \mathrm{ml}$, respectively. Recoveries from in vitro samples ranged from 91.0 to $114.0 \%$ and the precision of the method in terms of retention time (\%RSD $\leq 2.01)$ and peak area $(\% R S D \leq 5.11)$ were satisfactory. Conclusion: The validated RP-HPLC- PDA method can be used routinely for the determination of GPD in in vitro cultures and in vivo plants of G. kurroo.

Key words: Gentiopicroside, RP-HPLC method development, Validation, In vitro cultures, Gentiana kurroo.
\end{abstract}

\section{INTRODUCTION}

Gentiana kurroo Royle, generally referred to as the Indian or Himalayan Gentiana belongs to the family Gentianaceae and is included in the Indian medicinal codex. ${ }^{1,2}$ It grows naturally in the high-altitude regions of the western and northwestern Himalaya mountains. ${ }^{3}$ The roots of $G$. kurroo have been reported to contain gentiopicroside (GPD). ${ }^{4}$ Previous reports revealed that GPD has antibacterial and free radical scavenging ${ }^{5}$ analgesic, ${ }^{6}$ antiinflammatory, ${ }^{7,8}$ antinociceptive, ${ }^{9}$ and antidiabetic activities. ${ }^{10}$ It has also been used to treat acute jaundice and chronic active hepatitis. ${ }^{11}$ Therefore, it is important to quantify the GPD levels in the species of Gentiana using highly sensitive assays such as high-performance liquid chromatography (HPLC).

Previously, the HPLC-electrospray ionization tandem mass spectrometry (HPLC/ ESI-MS) was used to analyze GPD in G. lutea ${ }^{12}$ and Fourier transform infrared (FT-IR) spectroscopy was used for the determination of GPD in G. rigescens by selecting characteristic wavelengths along
Submission Date: 14-04-2021; Revision Date: 29-07-2021; Accepted Date: 09-11-2021.

DOI: 10.5530/ijper.56.1.31 Correspondence: Dr. T Kalaivani Associate Professor, Department of Biotechnology, School of Bio Sciences and Technology, Vellore Institute of Technology, Vellore-632014, Tamil Nadu, INDIA.

E-mail: tkvani72@gmail.com \#Equally contributed

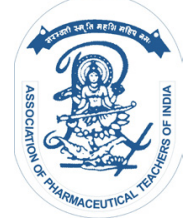

www.ijper.org 
with HPLC. ${ }^{13,14}$ Also, Pan et al..$^{15}$ used the LC-MS/MS and FT-IR to analyze the GPD in G. rigescens. Thin-layer chromatography (TLC) was used to investigate the GPD content in G. macrophylla, ${ }^{16}$ Centaurium erythrea and C. turcicum..$^{17}$

HPLC has been used to quantify the GPD in different stages of somatic embryos of $G$. macropbylla and $G$. straminea. ${ }^{16,18}$ The method was also used to compare the relative content of GPD in four Gentiana species, ${ }^{19,20}$ (G. macrophylla, G. straminea, G. dahurica and G. crassicaulis) and hairy root cultures of G. macrophylla, ${ }^{21} G$. cruciata L. ${ }^{22}$ and G. scabra. ${ }^{23}$ Also, GPD content was estimated using HPLC in G. straminea, ${ }^{24}$ and in the roots, stems, leaves and flowers of $G$. rigescens. ${ }^{25}$

Although MS/MS and Q-TOF-MS are highly precise and sensitive compared to PDA detectors, they are expensive and operationally tedious. On the other hand, HPLC with PDA is simple and more cost-effective than MS and can be routinely used for quantitative estimation of large number of samples. The PDA detector enables the UV scanning of every separated molecules, and detects molecules with a wide range of UV absorption and provides the UV spectrum of all the peaks. In contrast, a single fixed wavelength is used in UV detectors. Moreover, it has higher separation and precision than TLC and HPTLC. Hence in the present study, HPLC was used for GPD estimation.

Previous studies used different solvents as mobile phases with various HPLC conditions to separate and quantify the GPD; there was no consistency in elution time. Although GPD was analyzed by different methods in Gentiana species, no validated method was documented describing precise separation with high peak purity for quantification of GPD in in vitro samples of G. kurroo. Therefore, this study is focused on liquid chromatography coupled with a PhotodiodeArray (PDA) detector to establish and validate a simple method for quantitative analysis of the GPD in in vitro cultures and in vivo plants of G. kurroo.

\section{MATERIALS AND METHODS}

\section{Plant material}

Gentiana kurroo was collected from its natural habitat in Solan, Himachal Pradesh, during December 2018 and authenticated by Dr. R. Raina, Dr. Y. S Parmar University of Horticulture and Forestry, Solan, Himachal Pradesh. Previously established in vitro grown shoots, adventitious roots and callus cultures were harvested and used for analysis in this study.

\section{Reagents and chemicals}

Analytical grade methanol (Merck, Mumbai, India) was used for sample preparation. HPLC grade methanol, formic acid, acetic acid and $0.25 \mu \mathrm{m}$ nylon membranes were obtained from Merck (Bengaluru, India). The standard GPD ( $\geq 98 \%$ purity CID: 133550453) was purchased from Sigma -Aldrich (Mumbai, India). Milli-Q (Merck, Mumbai) purified water was practiced for the HPLC separation.

\section{Standards and plant sample preparation}

The authentic GPD stock solution of $1 \mathrm{mg} / \mathrm{ml}$ was prepared using HPLC grade methanol. Stock solutions of $10-100 \mu \mathrm{g} / \mathrm{ml}$ concentrations were prepared from the authentic stock solution. All the stock solutions were stored at $-4^{\circ} \mathrm{C}$. The in vitro plant samples, including callus, shoot and adventitious roots were harvested and washed thoroughly with water to remove the growth media and dried at $50^{\circ} \mathrm{C}$ for three days. In vivo grown rhizomes and shoots of G. kurroo were also washed with water to remove the soil particles.

The well dried in vitro and in vivo samples were powdered using a mortar and pestle. The GPD was extracted according to Dang et al. $^{24}$ with minor modifications. Exactly, $100 \mathrm{mg}$ of fine powder was added to a $2 \mathrm{ml}$ Eppendorf vial containing $1 \mathrm{ml}$ of HPLC grade methanol and sonicated for $20 \mathrm{~min}$ at $65^{\circ} \mathrm{C}$. The crude extract was centrifuged at $12000 \mathrm{rpm}$ for $15 \mathrm{~min}$ to remove the plant debris. The extracted sample was filtered through $0.25 \mu \mathrm{m}$ filters and directly used for HPLC analysis.

\section{Optimization of HPLC conditions}

HPLC tests were conducted on a Shimadzu-HPLC instrument (Shimadzu Corporation, Kyoto, Japan), fitted with a CBM-20A system, binary LC-20AP pump and SPD-M20A Photo Diode Array (PDA) detector. Chromatographic separation was achieved using Shimpack GIST $\mathrm{C}_{18}$ column $250 \times 4.6 \mathrm{~mm}$ and $5 \mu \mathrm{m}$ particle size (Shimadzu). The solvent mixture consisting of $1 \%$ acetic acid in water-methanol at 70:30 (v/v) was used as mobile phase. The solvents were degassed using an ultrasound sonicator bath (Sonica 2400 S3, Milan, Italy) and vacuum filtered through a $0.25 \mu \mathrm{m}$ nylon membrane (Merck). Precisely, $10 \mu \mathrm{l}$ of the sample was injected using a SIL-20AC HT Autosampler (Shimadzu). The isocratic elution was practiced at $1 \mathrm{ml} / \mathrm{min}$ flow to compare the GPD separation efficiency. The chromatogram peaks 
were identified by matching RT and UV spectra of authentic GPD. The acquired data were analyzed with LC-Solution tools (Shimadzu Corporation, Kyoto, Japan).

\section{Method validation procedure}

Ten different concentrations ranging from 10 to $100 \mu \mathrm{g} / \mathrm{ml}$ were used for the linear calibration plot for standard GPD. The concentrations of the authentic GPD compound were diluted with HPLC grade methanol. Each concentration of the calibration solution was injected into HPLC using SIL-20AC HT autosampler in triplicates. The peak area was plotted against the respective compound concentration, indicating the relative concentrations, was used as a calibration curve. The slope, intercept and correlation coefficient were calculated from the calibration curve, which was used to evaluate the GPD concentration in the sample, LOD and LOQ according to ICH guidelines. ${ }^{25}$

\section{Method precision, specificity and recovery}

To determine the relative retrievals, the homogenized in vitro shoots were spiked with three different known concentrations $(50,100$ and $200 \mu \mathrm{g} / \mathrm{ml}$ ) of standard GPD. The peak area of the spiked concentrations with the in vitro shoot sample solutions were compared with the respective standard GPD concentration levels to determine the exact percentage of the recovery. The inter-day precision was estimated by injecting the known standard and crude extracts at three different times within a day (morning at $10.00 \mathrm{am}$, afternoon at 1.30 $\mathrm{pm}$ and evening at $6.00 \mathrm{pm})$. The intra-day precision was analyzed by injecting the same sample for three days under similar instrumental conditions. The precision of the method was specified in relative standard deviation (RSD\%). The accuracy of the test was represented as the percentage of the compound concentration determined in the respective sample compared to the known quantity of the compound that spiked into the sample.

\section{Method sensitivity test}

The Limit of Detection (LOD approx.) and the limit of quantification (LOQ approx.) were estimated from the standard calibration curve using the following equations: $\mathrm{LOD}=3.3 \sigma / \mathrm{S}$ $\mathrm{LOQ}=10 \sigma / \mathrm{S}$

Where $\sigma$-represents the standard deviation of the intercept $\mathrm{S}$ - represents the slope of the calibration curve

\section{Robustness}

The analytical HPLC was performed at different chromatographic conditions to determine the robustness of this analytical method. The peak area was recorded at different $\lambda_{\text {max }}$ (wavelength) ranging from 245 to $275 \mathrm{~nm}$ and the mobile phase flow was tested from $0.5 \mathrm{ml} / \mathrm{min}$ to $1.2 \mathrm{ml} / \mathrm{min}$. The standard GPD $(10 \mu \mathrm{g} / \mathrm{ml})$ was injected in triplicate and the response was represented as $\%$ RSD.

\section{Statistical analysis}

Three replicates were performed for each parameter and the mean value of each experiment was calculated. All other statistical analyses were carried out using Microsoft Excel 2010.

\section{RESULTS}

\section{Optimization of analytical chromatographic conditions}

Several isocratic methods with different ratios of methanol and water mixtures, and with various flow rates were done to attain the ideal chromatographic conditions for the separation of GPD from the crude extract of G. kurroo. The finest separation with a relatively decent peak was achieved with the mobile phase containing a mixture of methanol - $1 \%$ acetic acid in water with the ratio of $30: 70(\mathrm{v} / \mathrm{v})$ at the flow rate of $1 \mathrm{ml} / \mathrm{min}$ (Figure 1d). The parameters tested for system suitability were listed in Table 1. Under these optimized settings, the standard GPD was also injected (Figure 2); it was eluted at $9.7 \pm 0.19$ min with a \% RSD of 2.01 . The complete elution of $G$. kurroo in vitro cultures and in vivo plant crude extracts with good separation of GPD was attained with 15 min run time under the abovedescribed system conditions. The peak of the GPD that separated at $9.7 \pm 0.19$ min was identified by comparing it to the RT and the UV spectrum of the standard (Figure 3). The lambda max for GPD was found to

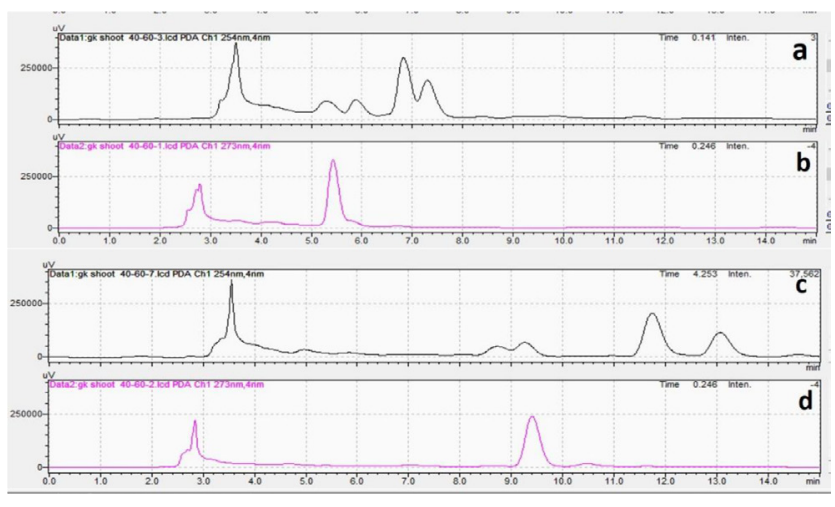

Figure 1: Efficiency of different mobile phase combination on separation of GPD from crude extract: a- $\mathrm{MeOH}-1 \%$ Acetic acid water (40:60) $0.8 \mathrm{ml} / \mathrm{min}$. b- $\mathrm{MeOH}-1 \%$ Acetic acid water (40:60) $1 \mathrm{ml} / \mathrm{min}$, c- MeOH $-1 \%$ Acetic acid water (30:70) $0.8 \mathrm{ml} / \mathrm{min}$, d- MeOH $-1 \%$ Acetic acid water (30:70) $1 \mathrm{ml} / \mathrm{min}$. 


\begin{tabular}{|c|c|c|}
\hline \multicolumn{3}{|c|}{ Table 1: Analytical HPLC system suitability } \\
parameters for GPD
\end{tabular}

*Mean of three replicates; ${ }^{\#} \%$ Relative standard deviation of three replication

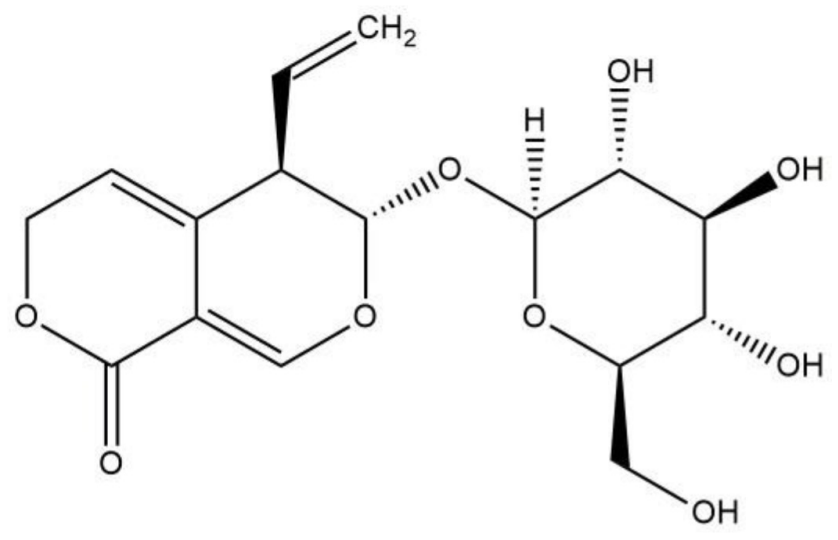

Figure 2: Chemical structure of GPD
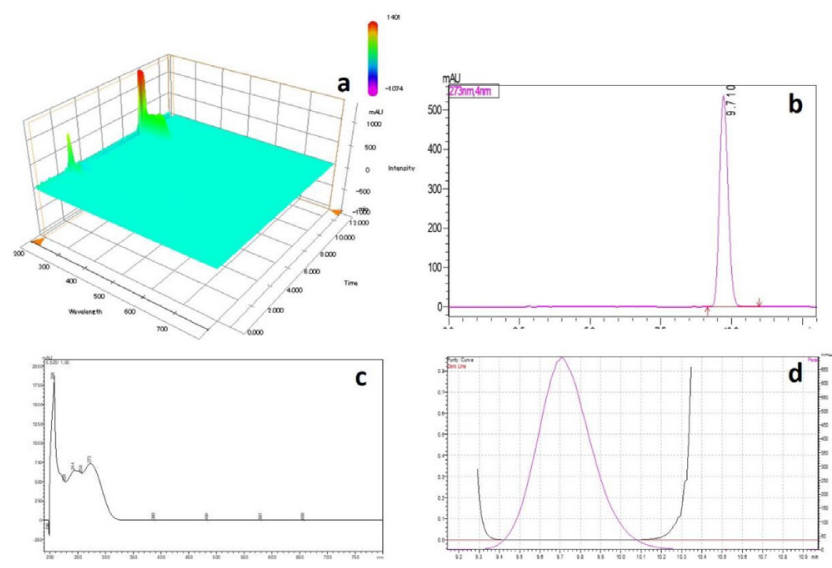

Figure 3: RP-HPLC elution of authentic GPD: a - 3D view, b Chromatogram, c - UV spectrum, d - purity index

be $273 \mathrm{~nm}$. The peak profile (Figure 4c) of the eluted GPD peak with reasonable resolution under the above conditions indicates that there was no interfering peak with the GPD and the purity index of GPD (Figure 4d) was $1 \pm 0.1$.
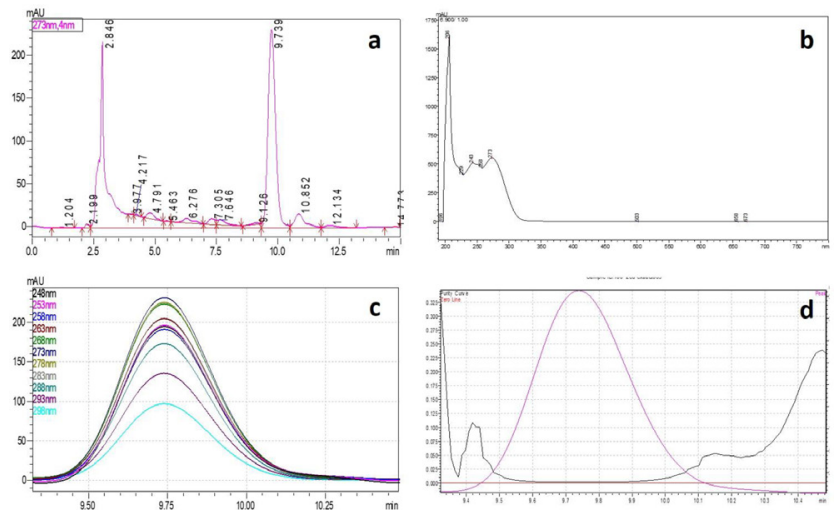

Figure 4: RP - HPLC separation of crude extract of G. kurroo: a - representative chromatogram of crude extract, b - UV spectrum at RT $9.73 \mathrm{~min}, \mathrm{c}$ - peak profile of GPD, d - purity index of peak at RT 9.73

\begin{tabular}{|c|c|}
\hline $\begin{array}{c}\text { Table 2: Analytical HPLC method validation } \\
\text { parameters for GPD }\end{array}$ \\
\hline Parameters & ${ }^{*}$ Mean values \pm STDVE \\
\hline Linearity & $10-100 \mu \mathrm{g} / \mathrm{ml}$ \\
\hline Regression equation & $\begin{array}{c}1,151,741.434 \mathrm{x}+ \\
1,748.978\end{array}$ \\
\hline Correlation coefficient & $R^{2}=0.999$ \\
\hline Accuracy & $99.30 \pm 2.79$ \\
\hline Repeatability Intra-day \\
\hline \multicolumn{2}{|c|}{ Inter-day } \\
\hline Std GPD & $99.78 \pm 0.42$ \\
\hline IV shoot extract & $99.10 \pm 1.46$ \\
\hline \multicolumn{2}{|c|}{$99.35 \pm 0.59$} \\
\hline Std GPD & $99.10 \pm 1.46$ \\
\hline IV shoot extract & $98.21 \pm 1.89$ \\
\hline Limit of Detection & $0.083 \mu \mathrm{g} / \mathrm{ml}$ \\
\hline Limit of Quantitation & $0.25 \mu \mathrm{g} / \mathrm{ml}$ \\
\hline
\end{tabular}

"Mean of three replicates

\section{Method validation}

The analytical HPLC method developed in this study was validated to meet the International Conference on Harmonization (ICH) guidelines (ICH Q2A 1994; ICH Q2B 1996). The developed HPLC conditions were examined for linearity, LOD, LOQ, accuracy, precision and peak purity. The validation parameters are represented in Table 2.

\section{Linearity and Sensitivity}

Better linearity was obtained between the peak area and different concentrations of GPD tested in the range of 10 to $100 \mu \mathrm{g} / \mathrm{ml}$ (Figure 5). The calculated coefficient of regression of the calibration curve for GPD was 


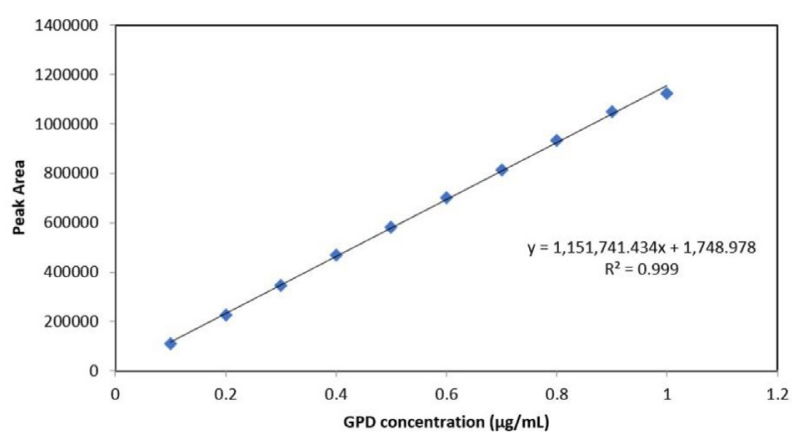

Figure 5: Standard graph of Gentiopicroside

\begin{tabular}{|c|c|c|}
\hline S. No. & Sample type & $\begin{array}{c}{ }^{*} \text { Quantity of GPD (mg/g } \\
\text { DW) }\end{array}$ \\
\hline 1 & Field shoot & $1.77 \pm 0.41$ \\
\hline 2 & Field root & $40.93 \pm 1.85$ \\
\hline 3 & Green House shoot & $2.27 \pm 0.80$ \\
\hline 4 & In vitro shoot & $8.48 \pm 0.99$ \\
\hline 5 & In vitro root & $1.84 \pm 0.34$ \\
\hline 6 & Callus & $1.57 \pm 0.48$ \\
\hline 7 & Suspension cells & $1.80 \pm 0.72$ \\
\hline
\end{tabular}

*Mean of three replicates

greater than 0.998 , which confirmed the linearity of the developed analytical method. The linear regression parameters of standard GPD are presented in Table 2. The calculated LOD and LOQ of GPD were found to be $0.083 \mu \mathrm{g} / \mathrm{ml}$ and $0.25 \mu \mathrm{g} / \mathrm{ml}$, respectively. These findings suggest that this analytical method has a high degree of sensitivity.

\section{Precision and accuracy}

The repeatability, precision and accuracy of the standardized method for GPD are presented in listed Table 2. The repeated injection of 5 different concentrations of the standard was $99.78 \pm 0.42$. The inter-day and intra-day precision of the standard GPD was $99.33 \pm 0.56$ and $99.33 \pm 0.56$, respectively and for the in vitro shoot extract $99.35 \pm 0.59$ and $98.97 \pm 0.84$, respectively. The accuracy of the established analytical method was identified by the addition of a known standard to the crude extract. The $\%$ RSD of recovery was $95 \%$ (95 to $110 \%$ ). The RP-HPLC procedure developed for GPD was found to be accurate and precise, as exhibited by the percentages of recovery tests close to 100 and $\%$ RSD not more than 4.

\section{Quantification of plant extract}

The different in vitro cultures and field plant methanolic extracts of G. kurroo were directly loaded into the HPLC system and the separation process was carried out at room temperature under the ideal chromatographic settings as described in the materials and methods section. The representative chromatogram (Figure 4a) shows the GPD peak at RT $9.73 \pm 1 \mathrm{~min}$, along with a few unidentified peaks. The GPD was separated from the crude extract efficiently and no overlapping peaks were observed with the GPD peak under this optimized method. Hence, the accuracy and validity of this developed method of analysis were not interfered with by the presence of unidentified peaks. The purity of the GPD peak separated in HPLC was compared with the authentic standard compound's UV-spectra and standard graph (Figure 5). The concentration of GPD in the different G. kurroo samples was quantitated using the above described analytical HPLC method (Table 3).

\section{DISCUSSION}

The HPLC method-based determination of GPD was reported previously by a few workers in gentian plants. ${ }^{16,19,22-24,26,27}$ However, to date, no single simple method was established and validated for the quantification of this compound in G. kurroo. In this study, we used different mobile phase ratios and flow rates for optimum separation of GPD from different plant material types of G. kurroo to rapidly and accurately quantify the GPD concentration. The mobile phase comprised of methanol and $1 \%$ acetic acid in water $(40: 60 \mathrm{v} / \mathrm{v})$ at 0.8 and $1 \mathrm{ml} / \mathrm{min}$ flow rate, eluted the GPD at 9.8 and $5.56 \mathrm{~min}$, respectively; however, the peak was closely merged with an unidentified peak (Figure 1 a and $\mathrm{b})$. The elution time of the GPD moved when the flow rate was reduced to $0.8 \mathrm{ml} / \mathrm{min}$, but no peak resolution was observed. In different trials, increasing the methanol ratio reduced the RT and resolution of the GPD separation from the crude extract. The finest separation with a good peak shape was achieved within 15 min when the crude extract was eluted with methanol and $1 \%$ acetic acid in water $(30: 70 \mathrm{v} / \mathrm{v})$ at $1 \mathrm{ml} / \mathrm{min}$ flow rate. $\mathrm{R}_{t}$ of 2.5 min was reported for the separation of GPD from G. straminea with a similar mobile phase. ${ }^{24}$ In this study, the $\mathrm{R}_{t}$ was observed at 9.73 min when $1 \%$ acetic acid was added to the mobile phase. The highest peak purity (purity index 1.0) with reasonable resolution and less tailing factor (Figure 3) was achieved with this mobile phase. The HPLC system suitability parameters also supported the acceptable chromatogram property 
with methanol: $1 \%$ acetic acid in water (30:70) at $1 \mathrm{ml} / \mathrm{min}$ (Table 1).

The above validated method was adopted for quantitative analysis of callus, suspension cells, adventitious roots, and wild plant shoot and rhizomes. The results showed varying concentrations of GPD (Table 3). Among the samples analyzed, the wild rhizomes showed the highest concentration of GPD (40.93 mg/g DW) followed by in vitro shoots (8.48). The high GPD levels in the in vivo plant's roots were perhaps due to the accumulation of GPD over many years. A similar result was reported in $G$. rigescens in which the concentration of GPD varied greatly among the different plant parts with the highest amount in the roots. The geographical locations of the plants also influenced the GPD accumulation. ${ }^{13,28}$ In addition, the biosynthesis of GPD was also organ specific. The expression of genes involved in the GPD synthesis was higher in leaves, ${ }^{29}$ and this may be the possible reason for the higher content of GPD in in vitro shoots.

This study demonstrated high specificity at $273 \mathrm{~nm}$ for GPD detection and high consistency in GPD quantification. The added advantages of this analytical procedure are rapid extraction, isocratic elution, the short run time within 15 min with no need for equilibration process between two consecutive elution and simple sample preparation.

\section{CONCLUSION}

HPLC analysis combined with a PDA detector was shown to be an efficient analytical procedure for the separation and quantitation of GPD in G. kurroo. The method was validated and showed that it is very basic, highly sensitive, reproducible and accurate. The detection limits are excellent for this compound. The extraction process of GPD can be applied to almost any plant tissue of G. kurroo. In addition, the chromatographic separation was carried out under isocratic conditions and did not require re-balancing between two successive HPLC runs.

\section{ACKNOWLEDGEMENT}

The authors express heartfelt gratitude to the Vellore Institute of Technology Management and the Dean SBST for their constant support and encouragements. The authors thank BRNS, DAE - Govt. of India for providing the financial support to A. Mariadoss Senior Research Fellow - grant no. 35/14/42/2014BRNS/2178.

\section{CONFLICT OF INTEREST}

The authors declare no conflict of interest.

\section{ABBREVIATIONS}

GPD: Gentipicroside; RP-HPLC: Reversed-Phase High-Performance Liquid Chromatography; TLC: Thin-Layer Chromatography; ESI-MS: Electrospray Ionization Tandem Mass Spectrometry; LC-MS: Liquid Chromatography-Mass Spectrometry; FT-IR: Fourier Transform Infrared; ICH: International Conference on Harmonization; RSD: Relative Standard Deviation; LOD: Limit of Detection; LOQ: Limit of Quantification; PDA: Photo Diode Array; DW: Dry Weight.

\section{REFERENCES}

1. Beherha MPC, Raina R. Gentiana kurroo Royle - A critically endangered bitter. Int J Arom Plants. 2012;2:22-9.

2. Skinder BM, Ganai BA, Wani AH. Scientific study of Gentiana kurroo Royle. Medicines (Basel). 2017;4(4):74. doi: 10.3390/medicines4040074, PMID 29023411.

3. Sharma A, Kaur R, Sharma N. In vitro morphogenic response of different explants of Gentiana kurroo Royle from Western Himalayas-an endangered medicinal plant. Physiol Mol Biol Plants. 2014;20(2):249-56. doi: 10.1007/ s12298-013-0220-4

4. Wani BA, Ramamoorthy D, Rather MA, Arumugam N, Qazi AK, Majeed R, et al. Induction of apoptosis in human pancreatic MiaPaCa-2 cells through the loss of mitochondrial membrane potential $\left(\Delta \Psi_{\mathrm{m}}\right)$ by Gentiana kurroo root extract and LC-ESI-MS analysis of its principal constituents. Phytomedicine. 2013;20(8-9):723-33. doi: 10.1016/j.phymed.2013.01.011, PMID 23453831.

5. Kumarasamy $Y$, Nahar L, Sarker SD. Bioactivity of gentiopicroside from the aerial parts of Centaurium erythraea. Fitoterapia. 2003;74(1-2):151-4. doi: 10.1016/s0367-326x(02)00319-2, PMID 12628413.

6. Chen L, Liu JC, Zhang XN, Guo YY, Xu ZH, Cao W, et al. Down-regulation of NR2B receptors partially contributes to analgesic effects of gentiopicroside in persistent inflammatory pain. Neuropharmacology. 2008;54(8):1175-81. doi: 10.1016/j.neuropharm.2008.03.007, PMID 18410946.

7. Mubashir K, Ghazanfar K, Ganai BA, Akbar S, Malik AH, Masood A. Scientific Validation of Gentiana kurroo Royle for anti-inflammatory and Immunomodulatory potential. ISRN Inflamm. 2014;2014:701765. doi: 10.1155/2014/701765.

8. Zhang Q, Zhang J, Xia P, Peng X, Li H, Jin H, et al. Anti-inflammatory activities of gentiopicroside against iNOS and COX-2 targets. Chin Herb Med. 2019;11(1):108-12. doi: 10.1016/j.chmed.2018.10.004.

9. Liu N, Li YX, Gong SS, Du J, Liu G, Jin SJ, et al. Antinociceptive effects of gentiopicroside on neuropathic pain induced by chronic constriction injury in mice: A behavioral and electrophysiological study. Can J Physiol Pharmacol. 2016;94(7):769-78. doi: 10.1139/cjpp-2015-0462, PMID 27175624.

10. Yang SQ, Chen YD, Li H, Hui X, Gao WY. Geniposide and gentiopicroside suppress hepatic gluconeogenesis via regulation of AKT-FOXO1 Pathway. Arch Med Res. 2018;49(5):314-22. doi: 10.1016/j.arcmed.2018.10.005, PMID 30409503.

11. Deng $\mathrm{Y}$, Wang L, Yang $\mathrm{Y}$, Sun W, Xie R, Liu X, et al. In vitro inhibition and induction of human liver cytochrome P450 enzymes by gentiopicroside: potent effect on CYP2A6. Drug Metab Pharmacokinet. 2013;28(4):339-44. doi: 10.2133/dmpk.dmpk-12-rg-090, PMID 23419353.

12. Mustafa AM, Caprioli G, Ricciutelli M, Maggi F, Marín R, Vittori S, et al. Comparative HPLC/ESI-MS and HPLC/DAD study of different populations of cultivated, wild and commercial Gentiana lutea L. Food Chem. 2015;174:42633. doi: 10.1016/j.foodchem.2014.11.089, PMID 25529701. 
13. Qi LM, Zhang J, Zhao YL, Zuo ZT, Jin H, Wang YZ. Quantitative and qualitative characterization of Gentiana rigescens Franch (Gentianaceae) on different parts and cultivations years by HPLC and FTIR spectroscopy. J Anal Methods Chem. 2017;2017:3194146. doi: 10.1155/2017/3194146, PMID 28656121.

14. Li S, Wan C, He L, Yan Z, Wang K, et al. Rapid identification and quantitative analysis of chemical constituents of Gentiana veitchiorum by UHPLC-PDAQTOF-MS. Rev Bras Farmacognosia. 2017;27(2):188-94. doi: 10.1016/j. bjp.2016.10.003.

15. Pan Y, Zhang J, Zhao YL, Wang YZ, Huang HY. Investigation of metabolites accumulation in medical plant Gentiana rigescens during different growing stage using LC-MS/MS and FT-IR. Bot Stud. 2015;56(1):14. doi: 10.1186/ s40529-015-0094-6, PMID 28510823.

16. Chen LY, Chen QL, Xu D, Hao JG, Schläppi M, Xu ZQ. Changes of gentiopicroside synthesis during somatic embryogenesis in Gentiana macrophylla. Planta Med. 2009;75(15):1618-24. doi: 10.1055/s-00291185808, PMID 19548190.

17. Nikolova-Damyanova B, Handjieva N. Quantitative determination of swertiamarin and gentiopicroside in Centaurium erythrea and C. turcicum by Densitometry. Phytochem Anal. 1996;7(3):140-2. doi: 10.1002/(SICl)10991565(199605)7:3<140::AID-PCA297>3.0.CO;2-0.

18. Yang $L$, Wang $H, H e ~ T$. Determination of gentiopicroside contents during somatic embryogenesis in Gentiana straminea Maxim. Acta Physiol Plant. 2014;36(7):1947-51. doi: 10.1007/s11738-014-1557-1.

19. Cao XY, Wang ZZ. Simultaneous determination of four iridoid and secoiridoid glycosides and comparative analysis of Radix Gentianae macrophyllae and their related substitutes by HPLC. Phytochem Anal. 2010;21(4):348-54. doi: 10.1002/pca.1206, PMID 20135711.

20. Zheng P, Zhang K, Wang Z. Genetic diversity and gentiopicroside content of four Gentiana species in China revealed by ISSR and HPLC methods. Biochem Syst Ecol. 2011;39(4-6):704-10. doi: 10.1016/j.bse.2011.06.002.

21. Zhang HL, Xue SH, Pu F, Tiwari RK, Wang XY. Establishment of hairy root lines and analysis of gentiopicroside in the medicinal plant Gentiana macrophylla. Russ J Plant Physiol. 2010;57(1):110-7. doi: 10.1134/S1021443710010152.
22. Hayta S, Gurel A, Akgun IH, Altan F, Ganzera M, Tanyolac B, et al. Induction of Gentiana cruciata hairy roots and their secondary metabolites. Biologia. 2011;66(4):618-25. doi: 10.2478/s11756-011-0076-4.

23. Huang SH, Vishwakarma RK, Lee TT, Chan HS, Tsay HS. Establishment of hairy root lines and analysis of iridoids and secoiridoids in the medicinal plant Gentiana scabra. Bot Stud. 2014;55(1):17. doi: 10.1186/1999-3110-55-17, PMID 28510924.

24. Dang J, Chen C, Shao Y, Mei L, Zhang H, Zhong Z, et al. Optimization of extraction technology of gentiopicroside from Gentiana straminea Maxim using response surface methodology on account of hplc. J Liq Chromatogr Relat Technol. 2014;37(14):1940-52. doi: 10.1080/10826076.2013.825853.

25. International Conference on Harmonization (ICH) Q2. (R1): Validation of analytical procedures: text and methodology. Available from: https://www.ich. org/page/quality-guidelines; November 2005.

26. Qi LM, Zhang J, Zhao YL, Zuo ZT, Jin H, et al. Quantitative and qualitative characterization of Gentiana rigescens Franch (Gentianaceae) on different parts and cultivations years by HPLC and FTIR spectroscopy. J Anal Methods Chem. 2017;2017:3194146. doi: 10.1155/2017/3194146, PMID 28656121.

27. Szucs Z, Dános B, Nyiredy Sz. Comparative analysis of the underground parts of Gentiana species by HPLC with diode-array and mass spectrometric detection. Chromatographia. 2002;56(1):S19-23. doi: 10.1007/BF02494108.

28. Li J, Zhang J, Zhao YL, Huang HY, Wang YZ. Comprehensive quality assessment based specific chemical profiles for geographic and tissue variation in Gentiana rigescens using HPLC and FTIR method combined with principal component analysis. Front Chem. 2017;5:125. doi: 10.3389/ fchem.2017.00125, PMID 29312929.

29. Liu Y, Wang Y, Guo F, Zhan L, Mohr T, Cheng P, et al. Deep sequencing and transcriptome analyses to identify genes involved in secoiridoid biosynthesis in the Tibetan medicinal plant Swertia mussotii. Sci Rep. 2017;7:43108. doi: 10.1038/srep43108, PMID 28225035.

\section{PICTORIAL ABSTRACT}

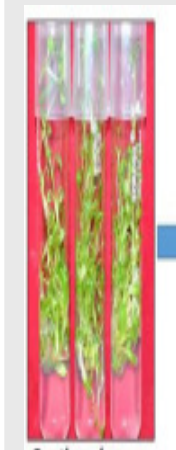

Gentionakurroo

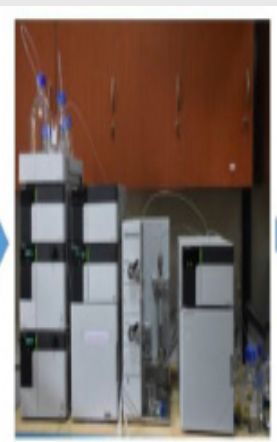

HPLC

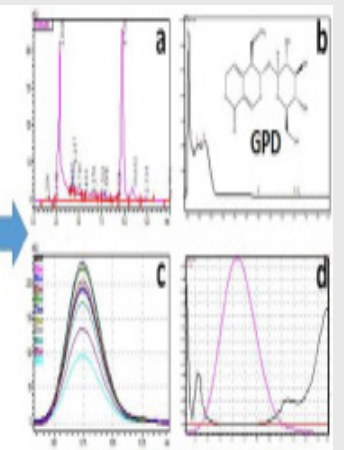

RP. HPIC separationof GPD

A simple, accurate, and highly sensitive reversed-phase high-performance liquid chromatographic (RP-HPLC) method was developed and validated according to the International Conference on Harmonization (ICH) guidelines for the secoiridoid glucoside, gentiopicroside for the first time. The method was validated for precision, specificity, and recovery and sensitivity. Methanol and $0.1 \%$ acetic acid in millipore water $[30: 70,(\mathrm{v} / \mathrm{v})]$ was the optimum ratio to perform an isocratic elution at $1.0 \mathrm{~mL} / \mathrm{min}$ under room temperature. The calibration curve was linear in the concentration range of 10-100 $\mu \mathrm{g} / \mathrm{mL}$ with a correlation coefficient of 0.9967 . The relative standard deviation (RSD) of repeatability and inter-day precision was less than $2 \%$. The limit of detection (LOD) and limit of quantification (LOQ) of GPD was $0.083 \mu \mathrm{g} / \mathrm{mL}$ and $0.25 \mu \mathrm{g} / \mathrm{mL}$, respectively. Recoveries from in vitro samples ranged from 91.0 to $114.0 \%$. The precision of the method in terms of retention time $(\% \mathrm{RSD} \leq 2.01)$ and peak area $(\% \mathrm{RSD}$ $\leq 5.11)$ were satisfactory. The validated RP-HPLCPDA method described in this present study can be used routinely to determine GPD content in in vitro and in vivo G. kurroo enabling a possible quality control technique. 


\section{About Authors}

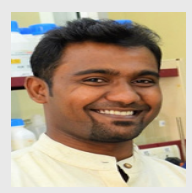

Mariadoss Alphonse has completed M.Phil. in Botany from St. Joseph's College Trichy and served at ICAR- National Research Center for Banana (NRCB), Trichy as a Technical Assistant in DST funded project. Later he joined VIT as a SRF in the BRNS- funded project. Currently pursuing Ph.D. in Plant Biology in the Department of Biotechnology, SBST, VIT, Vellore. His research interests are Natural Product Research, Ethnopharmacological Studies, In vitro production of Secondary Metabolites and Conservational Plant Biology.

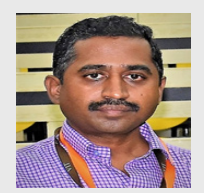

Dr. C. Rajsekaran is presently serving as Professor, School of Bio Sciences and Technology, VIT, India. He has completed Ph.D. in Plant Physiology from the High Altitude Plant Physiology Research Center \& G. B. Pant Institute of Himalayan Environment and Development. He is expertise in Eco Plant Physiology, Conservation Biodiversity, Bioprospecting of Medicinal and Aromatic Plants, Phycoremediation and Climate Change Indicators. He is fellow in vatious scientific bodies FSEDI, FLS (Lon), FRSB (UK), FISPP, FASCh. He is authors more than 80 research publications in reputed journals, 30 book chapters, many manographs, and edited books.

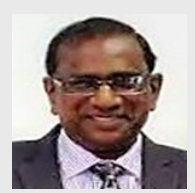

Dr. Michael Pillay completed Ph.D at Virginia Polytechnic Institute and State University and has completed three Post Doctoral Fellowships in USA. He is currently serving as Associate Editor of the Journal of Crop Improvement and editing manuscripts and thesis in Biotechnology, Plant Sciences, Molecular Genetics, Cell Culture/ Tissue Engineering, Chemistry, ITC, Health Sciences. He joined the Vaal University of Technology as a Professor in 2010, is the author and co-author of over 95 articles and book chapters.

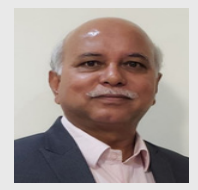

Dr. Devanand Fulzele is a Former-Senior Scientist, Head, Plant Biotechnology and Secondary Metabolites Section, Nuclear Agriculture and Biotechnology Division, BARC, Mumbai. Presently working as Research Advisor, Vellore Institute of Technology, Vellore and Visiting Professor in Bharat Institute of Higher Education and Research, Chennai, India.

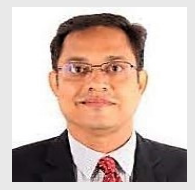

Dr. Siva Ramamoorthy is presently working as a Professor and Dean, School of Bio Sciences and Technology, VIT- Vellore, India. He did his postdoctoral research at Ben Gurion University (Israel) and Gyeongsang National University (South Korea). His fields of interests are Bioprospecting and Biodiversity of Natural Dyes. Prof. Siva is among Top 2\% Scientists of the World as per Mendeley.

T. Kalaivani is working as Associate Professor, School of Bio Sciences and Technology, VIT, India. She is expertise in Biochemistry and Plant Secondary Metabolites. Her research interests are Secondary Metabolites from Medicinal and Aromatic Plants, Toxicology and Bioremediation. She has published more than 50 research articles in reputed journals.

Cite this article: Mariadoss A, Rajasekaran C, Pillay M, Fulzele DP, Siva R, Kalaivani T. Development and Validation of a Precise RP- HPLC Method to Determine Gentiopicroside Content in Cultures of Gentiana kurroo Royle. Indian $\mathrm{J}$ of Pharmaceutical Education and Research. 2022;56(1):264-71. 